This item was submitted to Loughborough's Research Repository by the author.

Items in Figshare are protected by copyright, with all rights reserved, unless otherwise indicated.

\title{
Active control of dynamic platforms
}

PLEASE CITE THE PUBLISHED VERSION

PUBLISHER

Professional Engineering Publishing / @ IMECHE

VERSION

VoR (Version of Record)

LICENCE

CC BY-NC-ND 4.0

REPOSITORY RECORD

Rieger, K., and Kaddour Bouazza-Marouf. 2019. "Active Control of Dynamic Platforms". figshare. https://hdl.handle.net/2134/5142. 
This item was submitted to Loughborough's Institutional Repository (https://dspace.lboro.ac.uk/) by the author and is made available under the following Creative Commons Licence conditions.

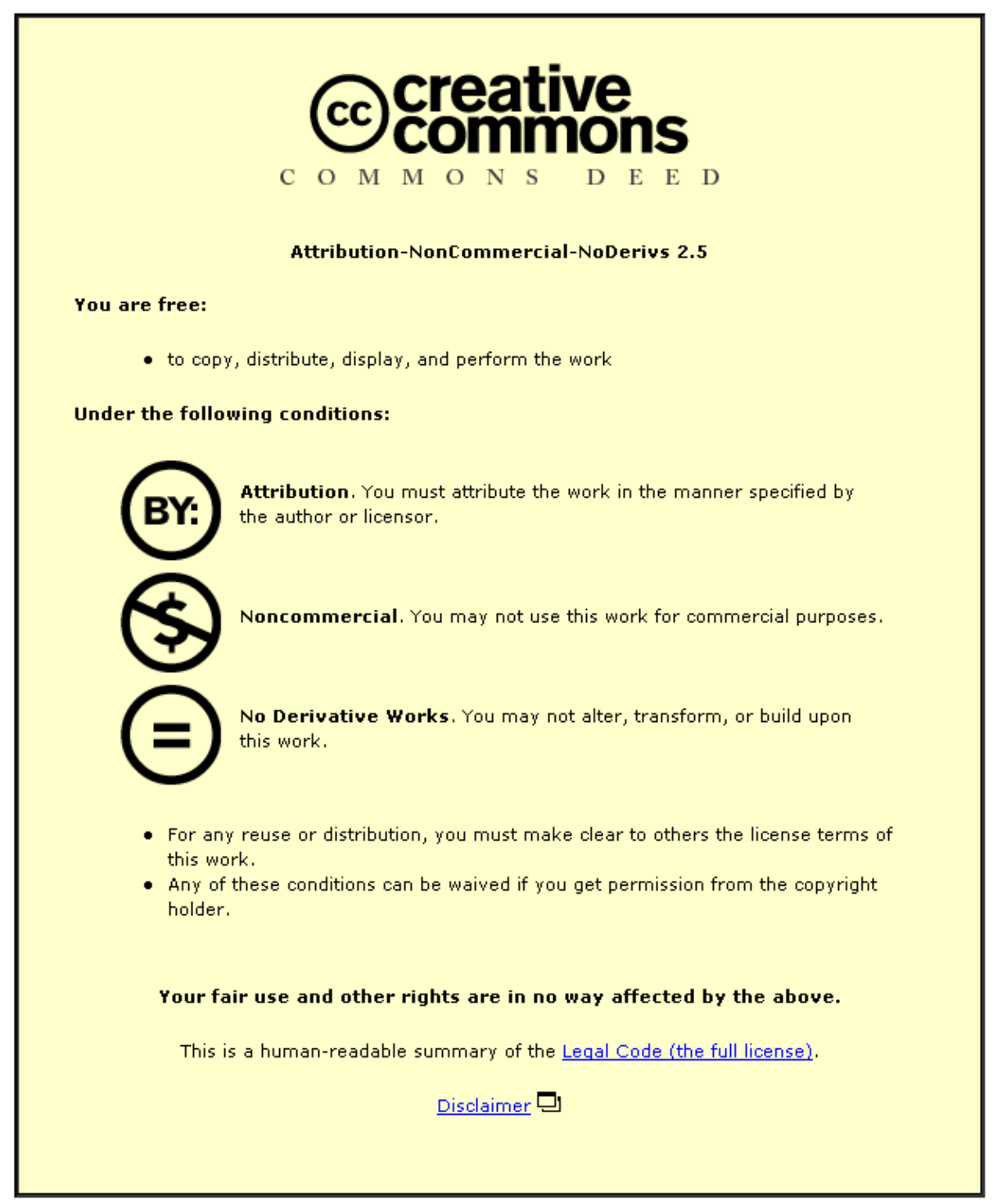

For the full text of this licence, please go to: http://creativecommons.org/licenses/by-nc-nd/2.5/ 


\title{
Active control of dynamic platforms
}

\author{
K Rieger* and K Bouazza-Marouf \\ Wolfson School of Mechanical and Manufacturing Engineering, Loughborough University, Loughborough, UK
}

The manuscript was received on 17 November 2004 and was accepted after revision for publication on 16 September 2005.

DOI: 10.1243/095965105X33662

\begin{abstract}
The control of a dynamic platform system for offshore operations in adverse weather conditions is discussed in this paper. The aim is to control the deck of the dynamic platform system to remain stationary irrespective of displacement-type base disturbances and force/ torque-type deck disturbances. Two control schemes based on the principle of invariance are described. Open-loop control, with drift cancellation, is implemented for the heave (vertical) motion, which is not always possible to obtain in practical systems. An experimental rig has been used to investigate and validate simulation results. Good simulation and experimental results have been obtained.
\end{abstract}

Keywords: active control, dynamic platform system, offshore, adverse weather

\section{INTRODUCTION}

The safety and performance of offshore operations are significantly affected by wave-induced disturbances. For example, it is very hazardous to transfer load or personnel between a fixed and a moving platform, or between two moving platforms, in adverse weather conditions. The presence of large wave disturbances makes these types of operations costly, difficult and dangerous; they pose a real challenge and the skills of a human operator are often relied upon. Certain operations are strictly time limited and do not allow for time delays in order to wait for suitable weather conditions. Hence, there is an increasing need for a system to allow safe crew changes and transportation as well as payload transfers in the offshore and marine applications.

Another problem caused by wave-induced motion is the control of offshore robotic systems. The inertial forces, induced by the base motion, result in performance loss. Different control strategies have been proposed but complete disturbance compensation has not been possible to achieve due to the nature of the disturbance [1].

The effect of adverse weather conditions on the ships' motion has been of great interest for many

\footnotetext{
* Corresponding author: Institute for Automatic Control, and Control Systems Technology, Johannes Kepler University Linz, Raschbach 10, Aurach am Hongar, Oberösterreich 4861, Austria. email: karl.rieger@gmx.at
}

years and different systems have been proposed/ implemented to reduce the wave-induced disturbances. Different types of attenuators and absorbers have been proposed $[2,3]$. Out of the six degrees of freedom (DOF) of the ship's motion, surge, sway, heave, roll, pitch, and yaw, only two motions, heave and pitch, have proved very difficult to overcome due the large forces involved [4-6]. Therefore, a dynamic platform system could be used to compensate for these two motions. In addition, such a system has an economical advantage in terms of energy consumption; instead of moving the whole vessel only the on-deck dynamic platform system could be operated.

The use of a dynamic platform, which is controlled to remain stationary irrespective of base-induced motion and payload changes, would be a solution to the above problems to allow maximum operation and improved safety. Therefore, such a platform could be used (a) to address the current offshore load transfer problems in adverse weather conditions, (b) as a helicopter landing platform, (c) as support platforms when a large structure is transported using more than one vessel, or (d) incorporated with a gangway system when there is a relative motion between two decks. This will allow the synchronization of the docking end of the gangway with the motion of the respective deck.

Bouazza-Marouf and Hewit [5] have described a novel concept of providing a dynamic platform system to compensate for the heave and pitch 
motions for offshore applications taking into account the practical implementation of such a system. By means of a mathematical model of the mechanism two control techniques, based on the principle of invariance, have been developed. The proposed control methods have been successfully applied to the control of keeping a two DOF platform stationary in the presence of measurable and immeasurable disturbances. However, there are some difficulties in the practical implementation of such control strategies as accurate and fast heave measurements may be difficult to obtain in some offshore applications. This, in combination with inaccuracies in parameter estimations, usually results in drift, which can be overcome by a human operator. This paper addresses new control strategies to overcome such problems and therefore improves the robustness of the system to avoid human interaction.

A drift compensation control scheme is presented in this paper in order to cancel or reduce drift of the dynamic platform. To compensate for system state drifts, the process of augmentation is used, whereby errors are compensated for by utilizing other independent system states. In other words, it is assumed that the drift is observable. Also, a system identification method for the non-linear dynamic platform system is used in the proposed control strategy. This estimation method could be performed in real-time and could be useful in relation to performance losses of initial system parameter-based control techniques. A full description of these control methods is given within section 4 .

\section{SYSTEM OVERVIEW}

The aim of the control scheme is to keep a platform stationary while cancelling the effect of external disturbances. To demonstrate the control strategy a platform actively suspended on a base by means of active actuators is used. A two DOF experimental rig, previously developed [5], is used to investigate the robustness of the proposed control schemes. A photograph and a schematic diagram of the dynamic platform system are shown in Figs 1 and 2 respectively. A cam-actuation system induces displacementtype disturbances to the base of the two DOF rig. The platform is actively suspended by two electromechanical actuators which are mounted on the base and are linked to the base and the platform by pin joints. The shaft of each electrical motor of the electromechanical actuators is connected with a flexible coupling to a ball screw. The base and platform motions are constrained to two DOF, heave,

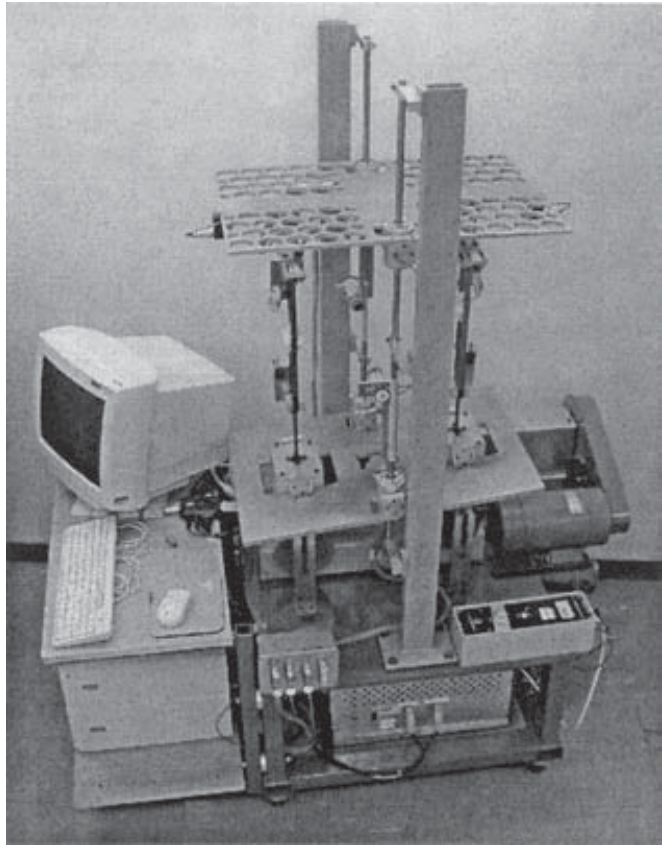

Fig. 1 Dynamic platform rig

and pitch, using joint assemblies attached to two stationary rods. The parallel configuration of this system provides high stiffness.

\section{MATHEMATICAL MODEL}

A similar mathematical model of the dynamic platform system, developed in Bouazza-Marouf and Hewit [5], is used. The equation of motion for a general dynamic platform system is given as

$$
\mathbf{M} \ddot{\boldsymbol{X}}=\mathbf{A} \boldsymbol{F}-\boldsymbol{F}_{\mathrm{D}}
$$

where

$$
\begin{aligned}
& \boldsymbol{X}=\left(\begin{array}{c}
x \\
\theta
\end{array}\right), \quad \boldsymbol{F}_{\mathrm{D}}=\left(\begin{array}{c}
F_{\mathrm{L}} \\
T_{\mathrm{L}}
\end{array}\right), \quad \boldsymbol{F}=\left(\begin{array}{c}
F_{1} \\
F_{2}
\end{array}\right) \\
& \mathbf{M}=\left[\begin{array}{cc}
M_{\mathrm{P}} & 0 \\
0 & J_{\mathrm{P}}
\end{array}\right], \quad \mathbf{A}=\left[\begin{array}{cc}
\sin \left(\alpha_{1}-\theta\right) & \sin \left(\alpha_{2}+\theta\right) \\
-R \sin \left(\alpha_{1}\right) & R \sin \left(\alpha_{2}\right)
\end{array}\right]
\end{aligned}
$$

Assuming identical actuators and considering the Coulombic friction force as an unknown disturbance the force vector $\boldsymbol{F}$ is derived as

$$
\begin{aligned}
\boldsymbol{F}= & K_{\mathrm{B}}\left(\boldsymbol{T}-\boldsymbol{T}_{\mathrm{E}}-\boldsymbol{T}_{\mathrm{F}}\right)-J_{\mathrm{A}} K_{\mathrm{B}}^{2} \mathbf{A}^{\mathrm{T}} \ddot{\boldsymbol{X}} \\
& -K_{\mathrm{B}}^{2} \boldsymbol{Q}(\boldsymbol{X}, \dot{\boldsymbol{X}}, \boldsymbol{Y}, \dot{\boldsymbol{Y}}, \ddot{\boldsymbol{Y}})
\end{aligned}
$$

where

$$
\begin{aligned}
& \boldsymbol{T}_{\mathrm{E}}=\frac{K_{\mathrm{B}} K_{\mathrm{T}} K_{\mathrm{E}}}{R_{\mathrm{T}}} \mathbf{A}^{\mathrm{T}} \dot{\boldsymbol{X}}, \quad \boldsymbol{T}_{\mathrm{F}}=K_{\mathrm{B}} C_{\mathrm{f}} \mathbf{A}^{\mathrm{T}} \dot{\boldsymbol{X}} \\
& \boldsymbol{T}=\frac{K_{\mathrm{T}}}{R_{\mathrm{T}}} \boldsymbol{V} \quad \text { with } \boldsymbol{V}=\left(\begin{array}{c}
V_{1} \\
V_{2}
\end{array}\right)
\end{aligned}
$$




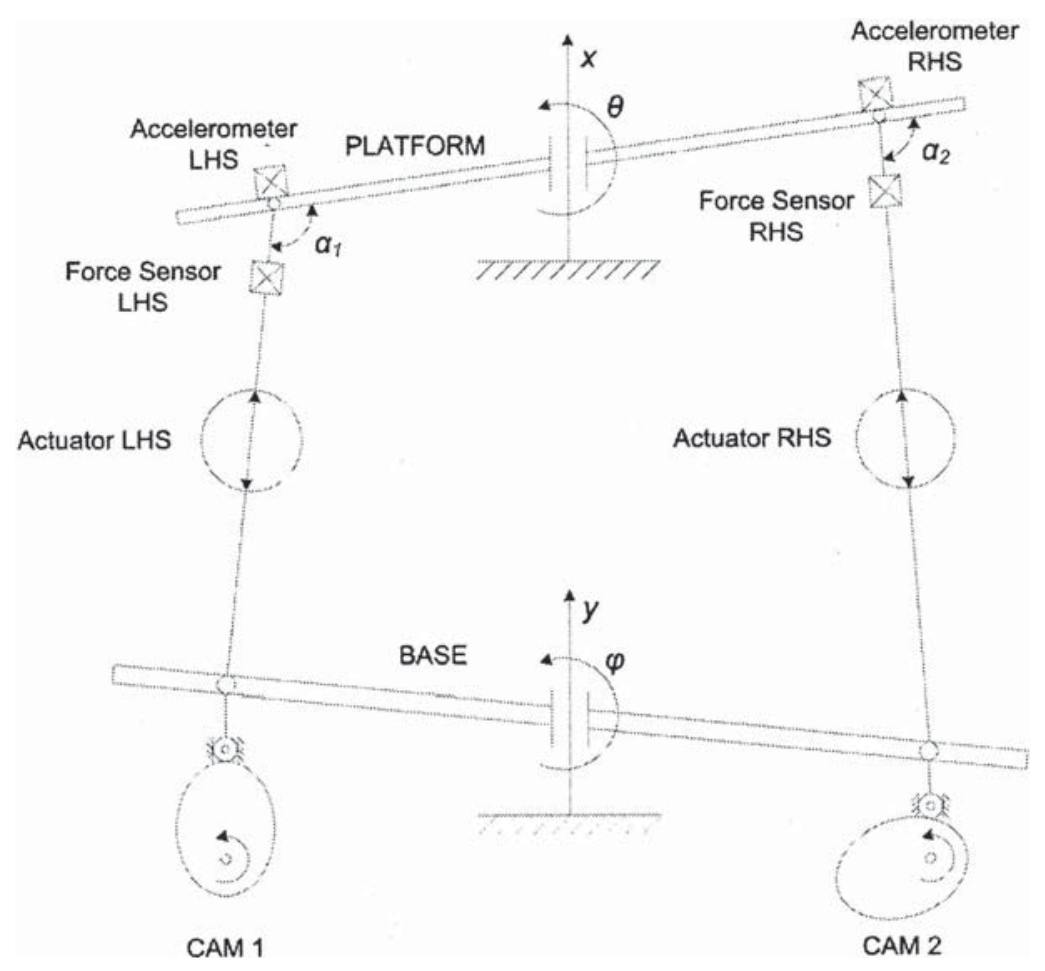

Fig. 2 Schematic diagram of the dynamic platform rig

Substituting for the force vector $\boldsymbol{F}$ the following equations can be obtained

$$
\begin{aligned}
\mathbf{M} \ddot{\boldsymbol{X}}= & \mathbf{A}\left[K_{\mathrm{B}}\left(\frac{K_{\mathrm{T}}}{R_{\mathrm{T}}} \boldsymbol{V}-\boldsymbol{T}_{\mathrm{E}}-\boldsymbol{T}_{\mathrm{F}}\right)-J_{\mathrm{A}} K_{\mathrm{B}}^{2} \mathbf{A}^{\mathrm{T}} \ddot{\boldsymbol{X}}-K_{\mathrm{B}}^{2} \boldsymbol{Q}\right] \\
& -\boldsymbol{F}_{\mathrm{D}}
\end{aligned}
$$

or

$$
\left(\mathbf{M}+J_{\mathrm{A}} K_{\mathrm{B}}^{2} \mathbf{A A}^{\mathrm{T}}\right) \ddot{\boldsymbol{X}}=\frac{K_{\mathrm{B}} K_{\mathrm{T}}}{R_{\mathrm{T}}} \mathbf{A} \boldsymbol{V}-\boldsymbol{F}_{\mathrm{TD}}
$$

where

$$
\boldsymbol{F}_{\mathrm{TD}}=K_{\mathrm{B}} \mathrm{A}\left(\boldsymbol{T}_{\mathrm{E}}+\boldsymbol{T}_{\mathrm{F}}\right)+K_{\mathrm{B}}^{2} \mathbf{A} \boldsymbol{Q}+\boldsymbol{F}_{\mathrm{D}}
$$

Equations (3) and (4) are shown in block diagram form in Figs 3 and 4.

\section{CONTROL STRATEGY}

Figure 5 shows the overall control strategy. The controller output vector $\boldsymbol{C}(=\boldsymbol{V})$ is chosen as

$$
\boldsymbol{C}=\boldsymbol{C}_{\mathrm{C}}+\boldsymbol{C}_{\mathrm{D}}
$$

where $\boldsymbol{C}_{\mathrm{C}}$ is derived from the system error and $\boldsymbol{C}_{\mathrm{D}}$ is the disturbance cancellation (or reduction) control vector. Two types of disturbance reduction controller schemes were illustrated in Bouazza-Marouf and Hewit [5]. In the following sections further control schemes are presented in order to cancel/reduce the effect of disturbances.

\subsection{Equilibrium point controller}

Effective position control of the dynamic platform at a desired point $\boldsymbol{X}=(a, b)^{\mathrm{T}}$ requires the cancellation

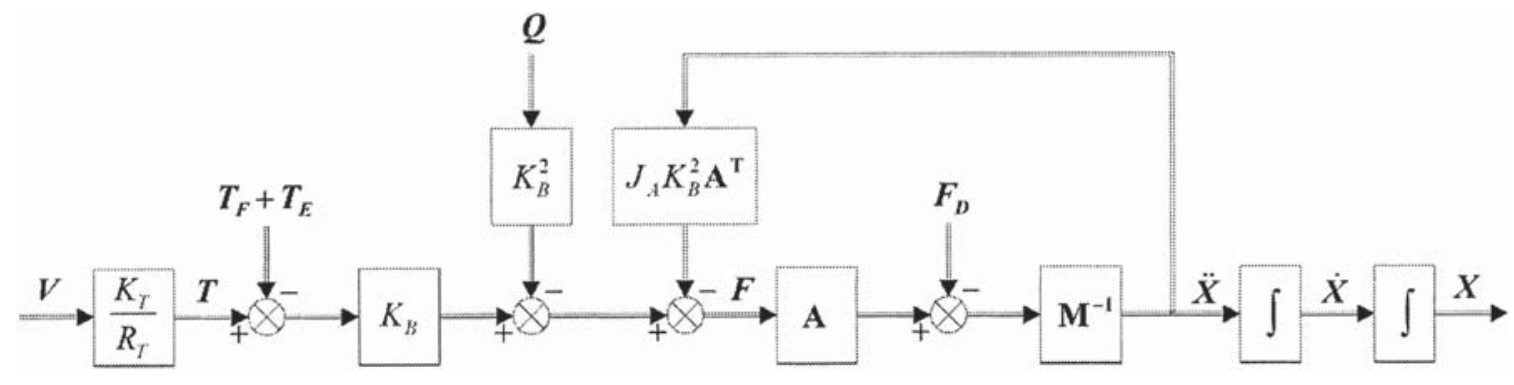

Fig. 3 Block diagram of equation (3) 


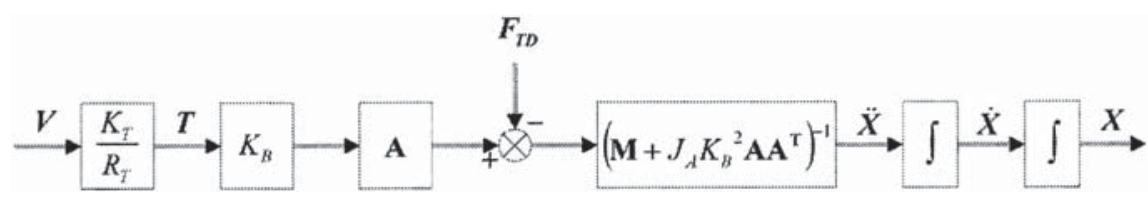

Fig. 4 Block diagram of equation (4)

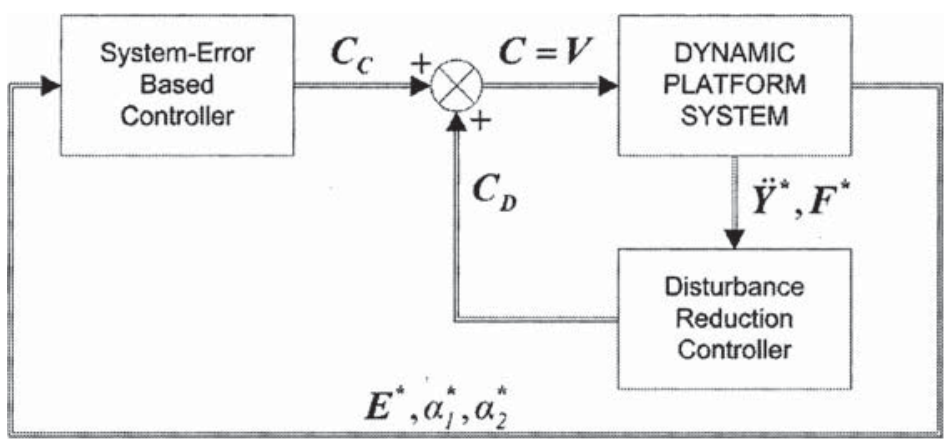

Fig. 5 Overall system control structure (the superscript * denotes on-line measured quantities)

of the disturbance vector $\boldsymbol{F}_{\mathrm{D}}$ in equation (1) as well as the base displacement disturbances. The latter disturbance can be cancelled using Feedforward control and the force disturbance $\left(\boldsymbol{F}_{\mathrm{D}}\right)$ can be cancelled using Equilibrium Point control. The specific desired vertical position, $a$, and angular position, $b$, could be chosen to be zero; i.e. the vertical and angular position measurements could be adjusted to read zero at the desired mean position of the platform.

Let $\boldsymbol{C}_{\mathrm{D}}$, the disturbance cancellation vector, be chosen as

$$
C_{\mathrm{D}}=\boldsymbol{C}_{\mathrm{FFW}}+\boldsymbol{C}_{\mathrm{E}}
$$

where $\boldsymbol{C}_{\mathrm{FFW}}$ is the feedforward control vector given as

$$
C_{\mathrm{FFW}}=C_{\mathrm{B}}+C_{\mathrm{F}}+C_{\mathrm{EMF}}
$$

with

$$
\begin{aligned}
& C_{\mathrm{B}}=\left(\frac{\hat{R}_{\mathrm{T}}}{\hat{K}_{\mathrm{T}}}\right) \hat{K}_{\mathrm{B}} \hat{J}_{\mathrm{A}}\left(\begin{array}{l}
\ddot{y}-\ddot{\phi} \hat{R} \cos \phi+\dot{\phi}^{2} \hat{R} \sin \phi \\
\ddot{y}+\ddot{\phi} \hat{R} \cos \phi-\dot{\phi}^{2} \hat{R} \sin \phi
\end{array}\right)^{*} \\
& C_{\mathrm{F}}=\left(\frac{\hat{R}_{\mathrm{T}}}{\hat{K}_{\mathrm{T}}}\right) \hat{K}_{\mathrm{B}} \hat{C}_{\mathrm{f}}\left(\begin{array}{c}
\dot{y}-\dot{\phi} \hat{R} \cos \phi \\
\dot{y}+\dot{\phi} \hat{R} \cos \phi
\end{array}\right)^{*} \\
& C_{\mathrm{EMF}}=\hat{K}_{\mathrm{B}} \hat{K}_{\mathrm{E}}\left(\begin{array}{c}
\dot{y}-\dot{\phi} \hat{R} \cos \phi \\
\dot{y}+\dot{\phi} \hat{R} \cos \phi
\end{array}\right)^{*}
\end{aligned}
$$

$\boldsymbol{C}_{\mathrm{B}}, \boldsymbol{C}_{\mathrm{F}}$, and $\boldsymbol{C}_{\mathrm{EMF}}$ compensate for the base-induced motion; they represent the inertia contribution, the viscous damping contribution, and the actuators' back e.m.f. contribution respectively. The superscript * denotes an on-line measured or estimated quantity and the superscript ^ denotes an off-line set-up measured or estimated quantity. The Feedforward control is used for the cancellation/reduction of the base disturbance (which is included in the disturbance vector $\boldsymbol{Q}$ ), the actuator's frictional torque vector $\boldsymbol{T}_{\mathrm{F}}$, and the actuator's back e.m.f. torque vector $\boldsymbol{T}_{\mathrm{E}}$. $\boldsymbol{C}_{\mathrm{E}}$ is for the Active Force loop vector [5], which should cancel the payload disturbances. A block diagram representation of this strategy is shown in Fig. 6.

It is assumed that the actuators' force vector $\boldsymbol{F}$ is composed as follows

$$
\boldsymbol{F}=\mathbf{L} \boldsymbol{F}+(\mathbf{I}-\mathbf{L}) \boldsymbol{F}=\mathbf{L} \boldsymbol{F}+\mathbf{H} \boldsymbol{F}=\boldsymbol{F}_{\mathrm{DC}}+\boldsymbol{F}_{\mathrm{AC}}
$$

where $\mathbf{I}$ is the identity matrix, $\mathbf{L}$ is a diagonal matrix representing the transfer functions of low-pass filters, and $\mathbf{H}$ is a diagonal matrix representing the transfer functions of high-pass filters. $\boldsymbol{F}_{\mathrm{DC}}$ and $\boldsymbol{F}_{\mathrm{AC}}$ represent the low- and high-frequency parts of the actuators' force vector respectively.

The main part of the platform disturbance is the payload disturbance. This can be estimated using the d.c. component of the actuators' force. The platform disturbance vector $\boldsymbol{F}_{\mathrm{D}}$ in equation (1) could be estimated to

$$
\boldsymbol{F}_{\mathrm{D}} \approx \mathrm{ALF}=\mathbf{A} \boldsymbol{F}_{\mathrm{DC}}
$$

Let $\boldsymbol{C}_{\mathrm{E}}$ in equation (6) be chosen as

$$
\boldsymbol{C}_{\mathrm{E}}=\frac{\hat{R}_{\mathrm{T}}}{\hat{K}_{\mathrm{T}} \hat{K}_{\mathrm{B}}} \mathbf{L} \boldsymbol{F}^{*}
$$




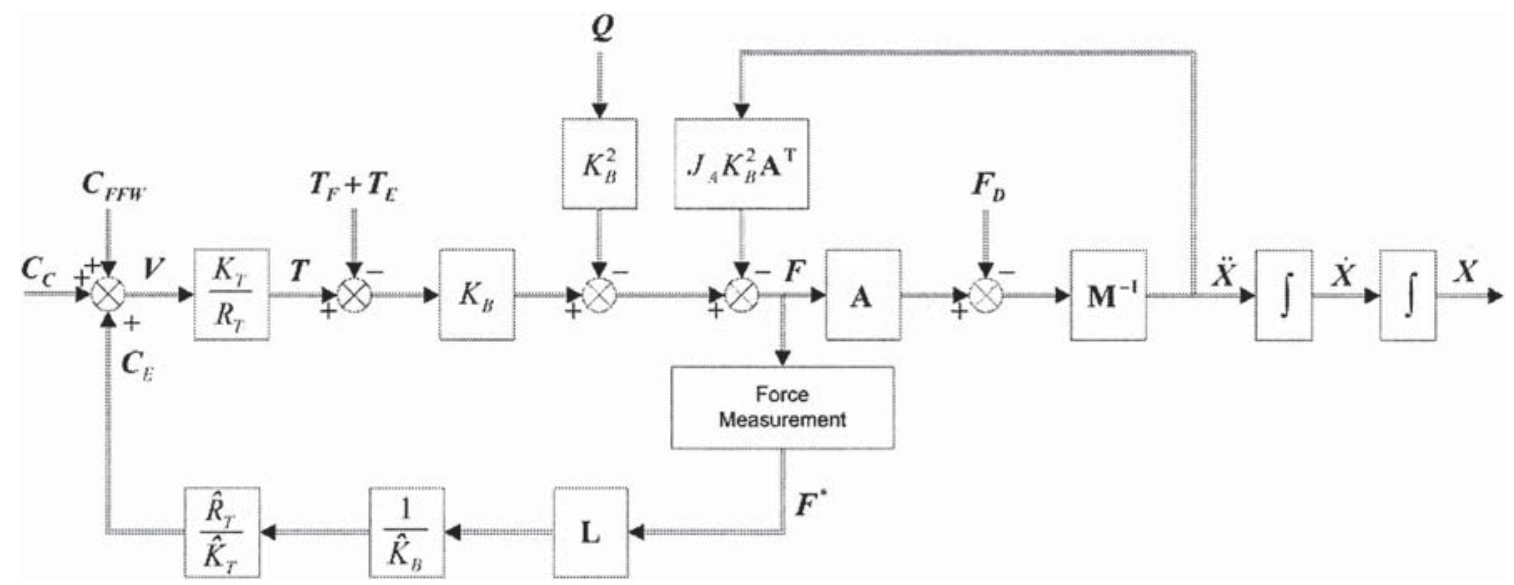

Fig. 6 Block diagram of the Equilibrium Point controller

Substituting the voltage input vector $\boldsymbol{V}$ in equation (3) by the controller output vector $\boldsymbol{C}$ in equation (5), and using equations (6), (7), and (10), it follows that

$$
\begin{aligned}
\mathbf{M} \ddot{\boldsymbol{X}}=\mathbf{A}\left[K _ { \mathrm { B } } \left(\frac{K_{\mathrm{T}}}{R_{\mathrm{T}}} \boldsymbol{C}_{\mathrm{C}}+\frac{K_{\mathrm{T}}}{R_{\mathrm{T}}} \boldsymbol{C}_{\mathrm{FFW}}+\frac{K_{\mathrm{T}}}{R_{\mathrm{T}}} \frac{\hat{R}_{\mathrm{T}}}{\hat{K}_{\mathrm{T}} \hat{K}_{\mathrm{B}}} \mathbf{L} \boldsymbol{F}^{*}\right.\right. \\
\\
\left.\left.-\boldsymbol{T}_{\mathrm{E}}-\boldsymbol{T}_{\mathrm{F}}\right)-J_{\mathrm{A}} K_{\mathrm{B}}^{2} \mathbf{A}^{\mathrm{T}} \ddot{\boldsymbol{X}}-K_{\mathrm{B}}^{2} \boldsymbol{Q}\right]-\boldsymbol{F}_{\mathrm{D}}
\end{aligned}
$$

Assuming that the control vectors $\boldsymbol{C}_{\mathrm{B}}, \boldsymbol{C}_{\mathrm{F}}$, and $\boldsymbol{C}_{\mathrm{EMF}}$ are adequate estimates then

$$
C_{\mathrm{B}}=\frac{R_{\mathrm{T}}}{K_{\mathrm{T}}} K_{\mathrm{B}} \boldsymbol{Q}, \quad \boldsymbol{C}_{\mathrm{F}}=\frac{R_{\mathrm{T}}}{K_{\mathrm{T}}} \boldsymbol{T}_{\mathrm{F}}, \quad \boldsymbol{C}_{\mathrm{EMF}}=\frac{R_{\mathrm{T}}}{K_{\mathrm{T}}} \boldsymbol{T}_{\mathrm{E}}
$$

Hence

$$
K_{\mathrm{B}} \frac{K_{\mathrm{T}}}{R_{\mathrm{T}}} C_{\mathrm{FFW}}=K_{\mathrm{B}}\left(\boldsymbol{T}_{\mathrm{E}}+T_{\mathrm{F}}\right)+K_{\mathrm{B}}^{2} \boldsymbol{Q}
$$

Therefore equation (11) becomes

$$
\begin{aligned}
& \left(\mathbf{M}+J_{\mathrm{A}} K_{\mathrm{B}}^{2} \mathbf{A A}^{\mathrm{T}}\right) \ddot{X} \\
& =\mathbf{A}\left[K_{\mathrm{B}}\left(\frac{K_{\mathrm{T}}}{R_{\mathrm{T}}} \boldsymbol{C}_{\mathrm{C}}+\frac{K_{\mathrm{T}}}{R_{\mathrm{T}}} \frac{\hat{R}_{\mathrm{T}}}{\hat{K}_{\mathrm{T}} \hat{K}_{\mathrm{B}}} \mathbf{L} \boldsymbol{F}^{*}\right)\right]-\boldsymbol{F}_{\mathrm{D}}
\end{aligned}
$$

and if the estimated and measured values are sufficiently accurate then

$$
\left(\mathbf{M}+J_{\mathrm{A}} K_{\mathrm{B}}^{2} \mathbf{A} \mathbf{A}^{\mathrm{T}}\right) \ddot{X}=\mathbf{A} K_{\mathrm{B}} \frac{K_{\mathrm{T}}}{R_{\mathrm{T}}} C_{\mathrm{C}}
$$

Therefore if the difference between $\mathbf{A L F}^{*}$ and $\boldsymbol{F}_{\mathrm{D}}$ is small, then ideally the choice of $\boldsymbol{C}_{\mathrm{C}}=0$ would result in $\ddot{\boldsymbol{X}}=0$. Figure 6 shows the block diagram of this control scheme. It should be noted that such control strategy will result in platform drift. This is discussed in section 4.2 below.
The illustrated control scheme has the same aim as the Active Force control loop described in BouazzaMarouf and Hewit [5] in order to cancel the platform disturbance vector $\boldsymbol{F}_{\mathrm{D}}$. However, in this paper the mass matrix is not used in the Active Force control loop to minimize parameter dependency. It should be noted that more than one Active Force control loop could be used in parallel.

\subsection{Drift compensation controller}

In all previously illustrated control schemes for the dynamic platform system it has been shown that if $\boldsymbol{C}_{\mathrm{C}}=0$ then $\ddot{\boldsymbol{X}}=0$. Hence, a small drift of the platform could result in the case when the dynamic platform is used for some offshore operations where measurements of $x$ and $y$ may be difficult to obtain. Previously [5] the position feedback loop was replaced by a visual feedback loop in order to overcome this disruptive drift. In this paper a controller scheme is illustrated to cancel the need for human interaction.

The Drift Compensation control utilizes the position difference vector $\boldsymbol{E}$, which represents the position vector of the platform with respect to the base datum frame; i.e. only relative position measurements (instead of absolute measurements) are used. Let the position difference vector $\boldsymbol{E}$ be given as

$$
E=X-Y
$$

The control vector $\boldsymbol{C}_{\mathrm{C}}$ can be chosen as

$$
\boldsymbol{C}_{\mathrm{C}}=\mathbf{G}_{\mathrm{P}} \frac{\hat{R}_{\mathrm{T}}}{\hat{K}_{\mathrm{T}}}\left(-\mathbf{A}^{-1} \mathbf{M}-\hat{J}_{\mathrm{A}} \hat{K}_{\mathrm{B}}^{2} \mathbf{A}^{\mathrm{T}}\right)^{*} \cdot \mathbf{L}_{\mathrm{E}} \cdot\left(\boldsymbol{E}^{*}-\boldsymbol{E}_{0}^{*}\right)
$$

where $\boldsymbol{E}_{0}$ is the initial position difference vector, $\mathbf{L}_{\mathrm{E}}$ is a diagonal matrix representing the transfer functions 
of low-pass filters, and $\mathbf{G}_{\mathrm{P}}$ is a diagonal matrix representing the drift compensation control gains. The estimate of $\boldsymbol{X}$ is given as

$$
\boldsymbol{X}^{*} \approx \mathbf{L}_{\mathrm{E}} \cdot\left(\boldsymbol{E}^{*}-\boldsymbol{E}_{0}^{*}+\boldsymbol{Y}_{m}\right)
$$

where $\boldsymbol{Y}_{m}$ is an arbitrary constant (which can be set to zero). The results of this scheme are discussed in section 6 .

It is not possible to avoid the sinusoidal component of the drift when the frequency of such drift and the frequency of the base motion are similar. To overcome this problem it is possible to use the estimate, $\boldsymbol{Y}^{*}$, of the base position. Thus equation (18) becomes

$$
X^{*} \approx \mathrm{L}_{\mathrm{E}} \cdot\left(E^{*}-E_{0}^{*}+Y^{*}\right)
$$

Here the constant $\boldsymbol{Y}_{m}$ has been replaced by the estimated base position $\boldsymbol{Y}^{*}$. $\mathbf{G}_{\mathrm{P}}$ can be chosen to satisfy classical feedback control. In addition, an integral loop could be added in order to cancel steady state errors. The control law for this scheme is therefore given as

$$
\begin{gathered}
\boldsymbol{C}_{\mathrm{C}}=\mathbf{G}_{\mathrm{P}} \frac{\hat{R}_{\mathrm{T}}}{\hat{K}_{\mathrm{T}}}\left(-\mathbf{A}^{-1} \mathbf{M}-\hat{J}_{\mathrm{A}} \hat{K}_{\mathrm{B}}^{2} \mathbf{A}^{\mathrm{T}}\right)^{*} \cdot \mathbf{L}_{\mathrm{E}} \cdot\left(\boldsymbol{E}^{*}-\boldsymbol{E}_{0}^{*}+\boldsymbol{Y}^{*}\right) \\
+\mathbf{G}_{\mathrm{I}} \int_{0}^{t}\left[\frac{\hat{R}_{\mathrm{T}}}{\hat{K}_{\mathrm{T}}}\left(-\mathbf{A}^{-1} \mathbf{M}-\hat{J}_{\mathrm{A}} \hat{K}_{\mathrm{B}}^{2} \mathbf{A}^{\mathrm{T}}\right)^{*}\right. \\
\left.\cdot \mathbf{L}_{\mathrm{E}} \cdot\left(\boldsymbol{E}^{*}-\boldsymbol{E}_{0}^{*}+\boldsymbol{Y}^{*}\right)\right] \mathrm{d} t
\end{gathered}
$$

where $\mathbf{G}_{\mathrm{I}}$ is a diagonal matrix representing the integral controller constants. The Drift Compensation controller could be used instead of a position feedback loop. The control scheme is shown as a block diagram in Fig. 7. For safety reasons, the position difference vector $\boldsymbol{E}$ is continuously observed, so that if it exceeds predefined boundaries of the dynamic platform system, an alarm is raised.

Two ways of base disturbance measurement have been illustrated in Bouazza-Marouf and Hewit [5]. The first method derived the quantities, absolute position and velocity, by integrating acceleration using a low-pass filter instead of a pure integrator. Better results were obtained from the second method based on the assumption of sinusoidal base disturbances. The base motion frequency $\omega$ was computed by sampling the base acceleration and $\omega$ was determined every half-cycle, every time $\ddot{y}=0$; i.e. there is a delay of a half-cycle in the computation of $\omega$. The calculation of $y$ and $\dot{y}$ assume that each half-cycle is part of a sinusoidal waveform, and the frequency $\omega$ remains constant or varies by a small amount between two consecutive half-cycles. The estimation of the other base velocities and positions could be derived in the same way.

The above technique can be extended to sinusoidal quarter-cycles. Thereby $\omega$ is computed every time when $\ddot{y}$ is zero, and when $\ddot{y}$ is maximal or minimal. The time, $T_{\mathrm{Q}}$, taken between the latter mentioned instances is used to obtain the base motion frequency $\omega$, which is given by $\omega=(\pi / 2) T_{\mathrm{Q}}$. The velocity, $\dot{y}$, and the position, $y$, are derived as

$$
\begin{aligned}
& \dot{y}_{t}=-\frac{1}{\omega} \ddot{y}_{t-(\pi / 2 \omega)} \\
& y_{t}=-\frac{\ddot{y}}{\omega^{2}}
\end{aligned}
$$

Additionally, an induced phase shift $\phi$ can be compensated. The corrected absolute velocity and position are given as

$$
\begin{aligned}
& \dot{y}_{t}=-\frac{1}{\omega} \ddot{y}_{t-[(\pi-2 \phi) /(2 \omega)]} \\
& \dot{y}_{t}=-\frac{1}{\omega^{2}} \ddot{y}_{t-[(\pi-\phi) /(2 \omega)]}
\end{aligned}
$$

The latter lag-correction technique may be used only for constant and slowly varying base disturbance frequencies because this technique induces longer phase shifts.

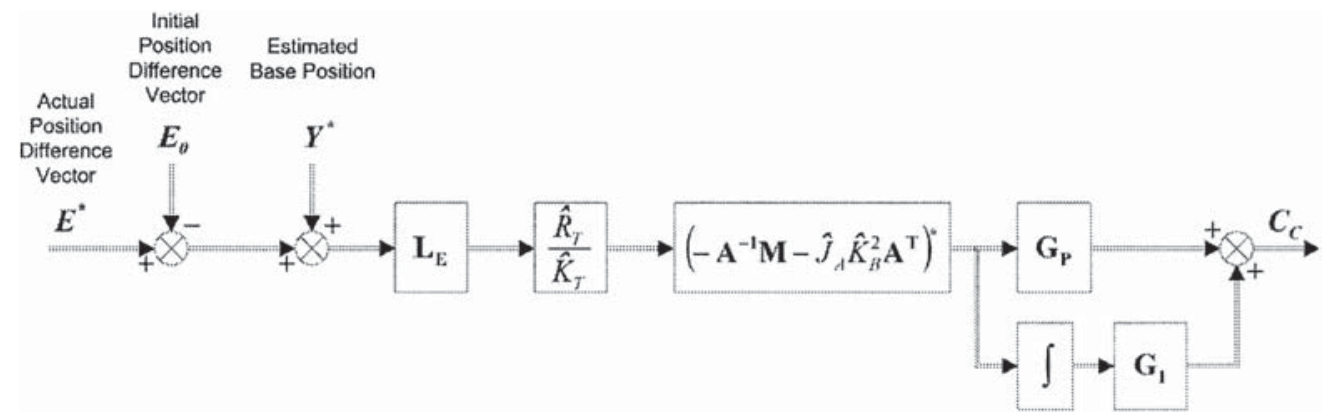

Fig. 7 Block diagram of the Drift Compensation controller 


\subsection{System identification}

The inefficiency of all illustrated controllers is associated with insufficiently accurate system parameters, whether it is caused by wrong computation or payload changes. Primarily this involves two parameters, the platform mass $M_{\mathrm{P}}$ and the platform inertia $J_{\mathrm{P}}$. Here, a method is illustrated to identify the system automatically and in real-time. Other methods like the non-linear least-square or subspace identification methods suffer from correlated actuator inputs, the restriction to single-input single-output (SISO) systems and the parameter estimation in design-time (rather than in real-time) [7].

Substituting the actuators' force vector $\boldsymbol{F}$ in equation (1) using equation (8), the following equation can be derived

$$
\mathbf{M} \ddot{\boldsymbol{X}}=\mathbf{A}\left(\boldsymbol{F}_{\mathrm{DC}}+\boldsymbol{F}_{\mathrm{AC}}\right)-\boldsymbol{F}_{\mathrm{D}}
$$

Also, as

$$
\mathrm{A} F_{\mathrm{DC}} \approx F_{\mathrm{D}}
$$

then

$$
\mathbf{M} \ddot{\boldsymbol{X}}=\mathbf{A} \boldsymbol{F}_{\mathrm{AC}}
$$

As the mass matrix is diagonal, the platform mass $M_{\mathrm{P}}$ and the platform inertia $J_{\mathrm{P}}$ are consequently obtained by

$$
\left[\begin{array}{c}
M_{\mathrm{P}} \\
J_{\mathrm{P}}
\end{array}\right]=\left[\begin{array}{cc}
\ddot{x}^{-1} & 0 \\
0 & \ddot{\theta}^{-1}
\end{array}\right] \mathbf{A} \boldsymbol{F}_{\mathrm{AC}}
$$

It can be noted that in equation (27) above if $\ddot{\boldsymbol{X}}=0$, then $M_{\mathrm{P}}=\infty$ or $J_{\mathrm{P}}=\infty$ and if $\boldsymbol{F}_{\mathrm{AC}}=0$, then $M_{\mathrm{P}}=0$ or $J_{\mathrm{P}}=0$. Therefore, the acceleration vector $\ddot{\boldsymbol{X}}$ components and the force vector $\boldsymbol{F}$ components must exceed a predefined limit to be relevant for the identification algorithm. Therefore the parameter identification is performed only when $\ddot{\boldsymbol{X}} \neq 0$ and $\boldsymbol{F}_{\mathrm{AC}} \neq 0$. The identification process itself may not be fault-prone due to phase shifts as long as the acceleration vector $\ddot{\boldsymbol{X}}$ and the force vector $\boldsymbol{F}$ experience the same lag. Hence, lower cut-off frequencies or higher-order filters may affect the reaction time on system parameter changes. The system identification could be performed parallel to the control algorithms and updates the control parameters in real-time. Figure 8 shows the system identification control structure.

\section{EXPERIMENTAL SET-UP}

The experimental rig, shown in Figs 1 and 2, is controlled using a Pentium $166 \mathrm{MHz}$ personal computer running a QNX 4.25 real-time operating system [8]. A schematic of the control system is shown in Fig. 9. The rig instrumentation allows measurements of the platform position vector $\boldsymbol{X}$, the base position

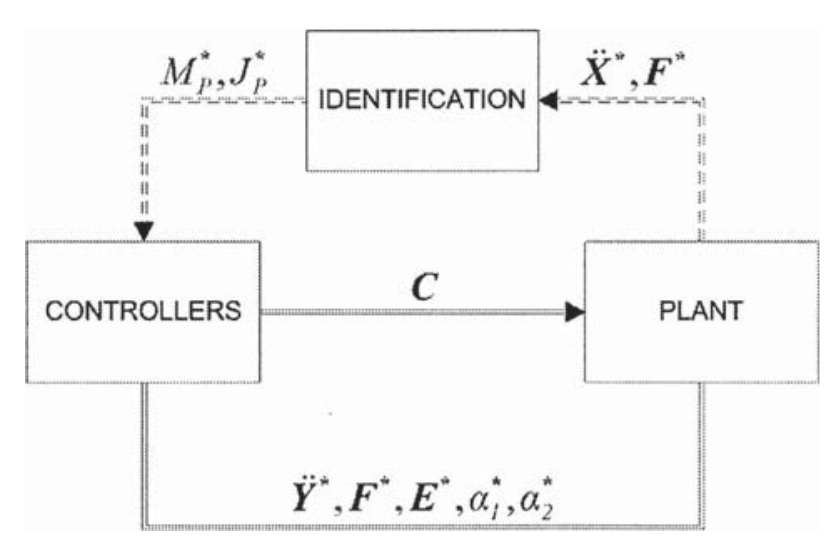

Fig. 8 System identification control structure

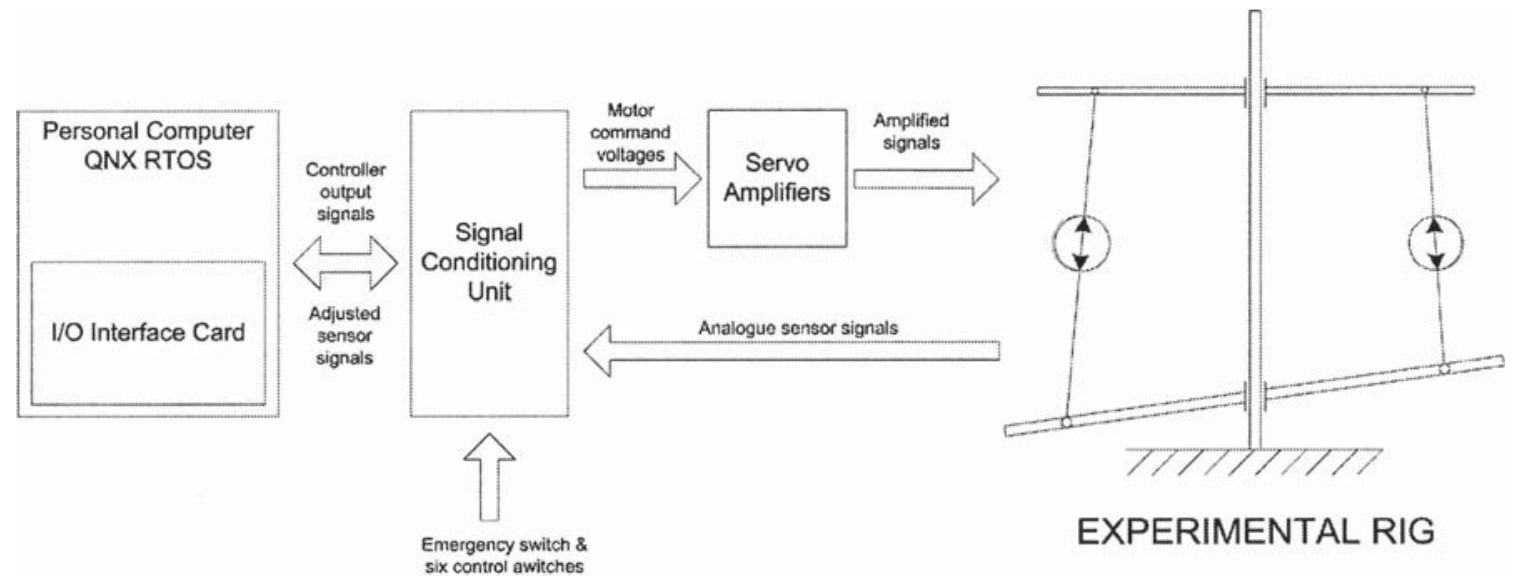

Fig. 9 Schematic overview of the control system 
vector $\boldsymbol{Y}$, the actuators' force vector $\boldsymbol{F}$, the platform acceleration vector $\ddot{\boldsymbol{X}}$, base acceleration vector $\ddot{\boldsymbol{Y}}$, the angles between the platform and the actuators $\alpha_{1}, \alpha_{2}$, and the motor torque vector $\boldsymbol{T}_{\mathrm{M}}$. Angular position measurements are obtained using rotary potentiometers, whereas vertical positions are determined through rotary potentiometers driven by a wheel rolling in contact with a stationary vertical rod. The position difference vector $\boldsymbol{E}$ is obtained by subtraction of the platform position vector $\boldsymbol{X}$ and the base position vector $\boldsymbol{Y}$. A general design overview is provided in Bouazza-Marouf and Hewit [5]. The numerical values of the system parameters are shown in Table 1.

The design of the actuators incorporates a force sensor. The force measurement is derived from a beam deflection using four strain gauges, in a Wheatstone bridge configuration, arranged at its mid-length. Additionally, the motor output torque is accomplished by measuring the armature current. Both ends of the base and the platform are instrumented with an accelerometer each. These accelerometers are of active closed-loop type and capable of detecting low-frequency motion.

The dynamic platform rig is controlled by recording all analogue signals with 12-bit analogue-todigital converters, generating analogue signals with 12-bit digital-to-analogue converters and using digital transistor-transistor logic (TTL)-level inputs. Figure 5 shows a block diagram of the overall system. Additionally, a signal conditioning unit (interface electronics) between the computer and the rig performs required signal conditioning and decouples the computer from the rest of the system. It incorporates buffers and gain adjustments for all analogue signals as well as second-order Butterworth filters for acceleration, force, and current measurements. The active low-pass filters prevent aliasing and reduce measurement noise.

Six control switches are provided for the selection of different control schemes/algorithms. The control algorithms are written in $\mathrm{C}++$ compiled by a Watcom $\mathrm{C} / \mathrm{C}++$ compiler. The frequency of the control loop is set to $1.5 \mathrm{kHz}$.

Table 1 System parameters

\begin{tabular}{lll}
\hline Parameter & Symbol & Value \\
\hline Viscous friction coefficient & $C_{\mathrm{f}}$ & $5 \times 10^{-6} \mathrm{~N} \mathrm{~m} \mathrm{~s} / \mathrm{rad}^{2}$ \\
Inertia of actuator & $J_{\mathrm{A}}$ & $4.35 \times 10^{-9} \mathrm{~kg} \mathrm{~m} \mathrm{~m}^{2}$ \\
Inertia of platform & $J_{\mathrm{P}}$ & $0.37326 \mathrm{~kg} \mathrm{~m}$ \\
Gear ratio of ball screw & $K_{\mathrm{B}}$ & $1570.8 \mathrm{rad} / \mathrm{m}$ \\
Motor back e.m.f. constant & $K_{\mathrm{E}}$ & $0.0478 \mathrm{~V} \mathrm{~s} / \mathrm{rad}$ \\
Motor torque constant & $K_{\mathrm{T}}$ & $0.04802 \mathrm{~N} \mathrm{~m} / \mathrm{A}$ \\
Mass of platform & $M_{\mathrm{P}}$ & $9.1392 \mathrm{~kg}$ \\
Distance between platform centroid and actuator joint on the platform & $R$ & $0.2 \mathrm{~m}$ \\
Ball screw mean radius & $R_{\mathrm{B}}$ & $0.00525 \mathrm{~m}$ \\
Motor terminal resistance & $R_{\mathrm{T}}$ & $1.5 \Omega$ \\
\hline
\end{tabular}

a)

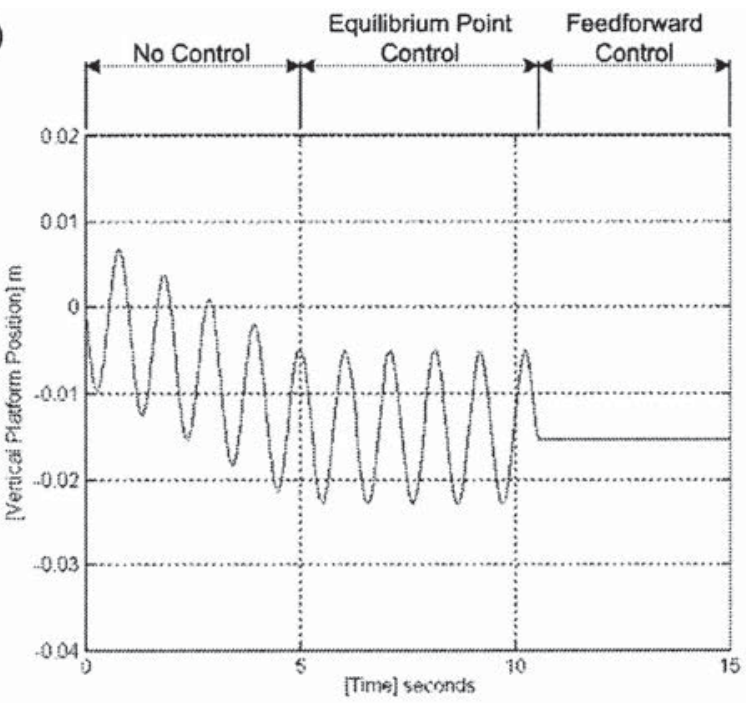

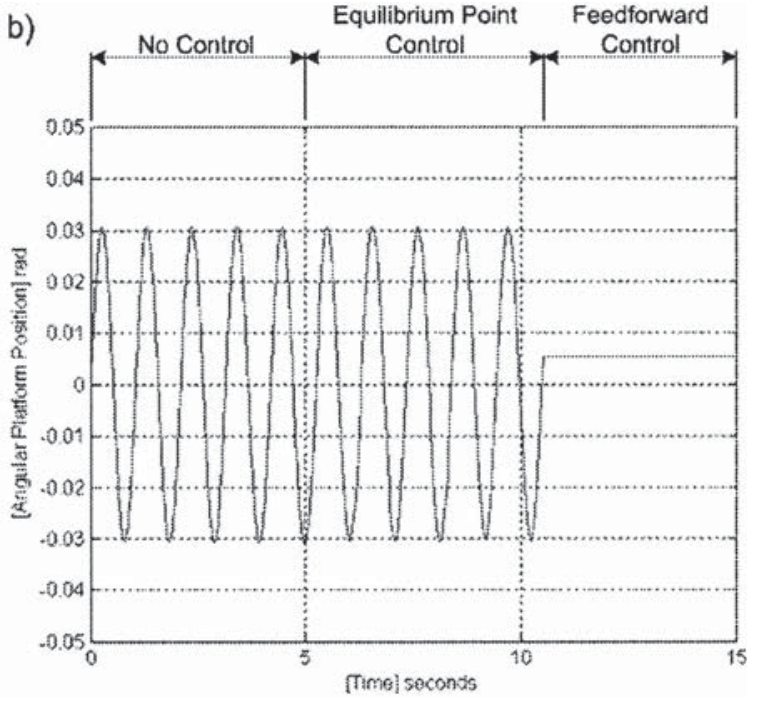

Fig. 10 Simulation results of the Equilibrium Point controller: (a) vertical platform position, $x$; (b) angular platform position, $\theta$ 


\section{RESULTS AND DISCUSSION}

\subsection{Simulation results}

The simulation results in Figs 10 and 11 show the ideal response of a dynamic platform for the control strategies, namely Equilibrium Point control and Drift Compensation control. The base disturbance input vector $\boldsymbol{Y}$ is a pure sinusoidal heave $y$ and pitch $\varphi$ motion vector at a frequency of $6 \mathrm{rad} / \mathrm{s}$, whereas the platform disturbance input vector $\boldsymbol{F}_{\mathrm{D}}$ consists of a gravity force vector in the $x$ direction.

In Fig. 10, the active control algorithm of section 4.1 was applied to a dynamic platform model with no positional feedback. Up until 5 seconds no controller was used and the heave and pitch motion of the

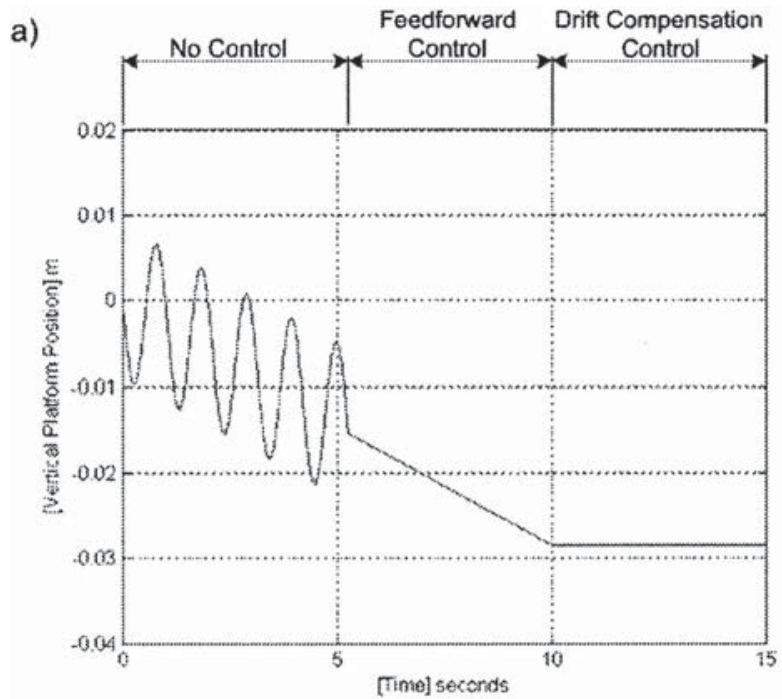

platform and the vertical drift could be clearly seen. After 5 seconds the Equilibrium Point control is introduced, resulting in total attenuation of the gravity force caused drift. Finally, after 10.5 seconds the Feedforward controller cancels all the platform's heave and pitch motion.

In Fig. 11, the Feedforward loop from section 4.1 and the Drift Compensation controller were applied to a dynamic platform model with no positional feedback. Up until 5 seconds only base disturbance was input. Afterwards, Feedforward control was added and complete base motion isolation was achieved. After 10.5 seconds the vertical drift was completely attenuated by the Drift Compensation control.

In Fig. 12, the system identification is performed on a dynamic platform model. After 4 seconds, good

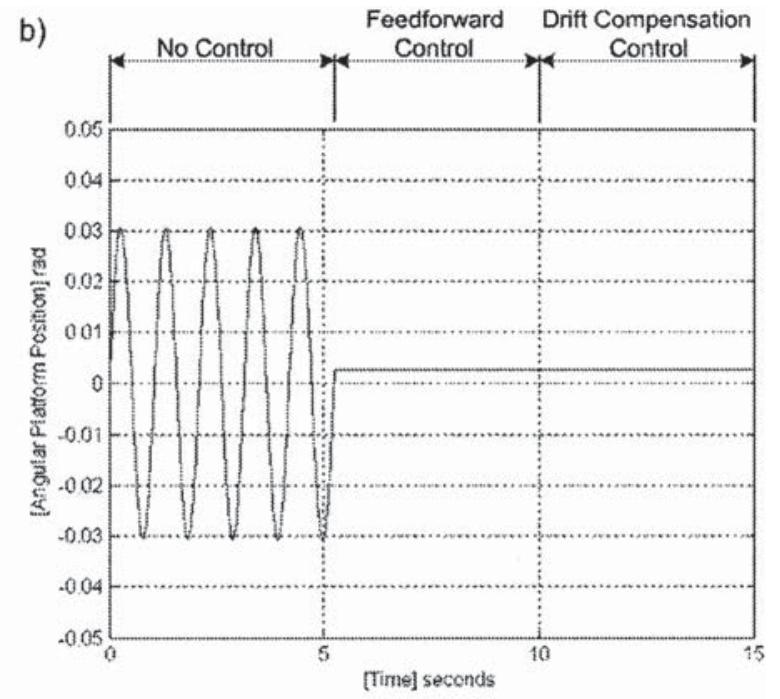

Fig. 11 Simulation results of the Drift Compensation controller and the Feedforward controller: (a) vertical platform position, $x$; (b) angular platform position, $\theta$

a)

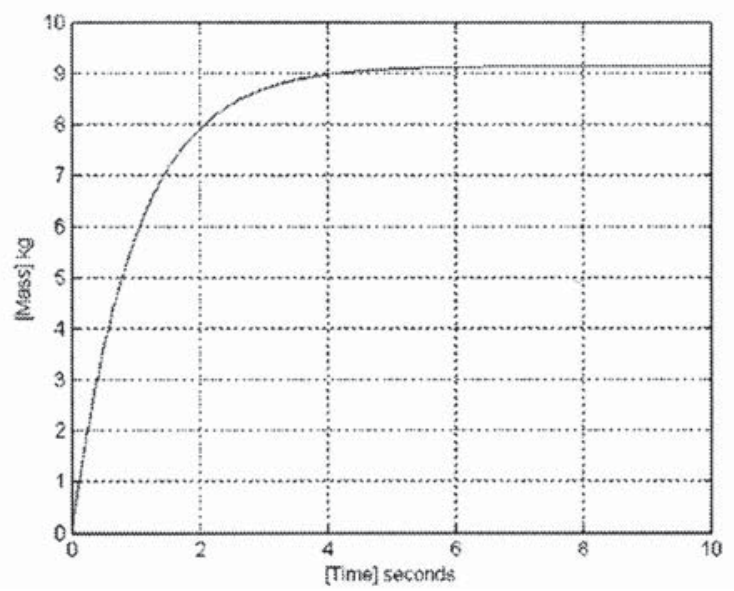

b)

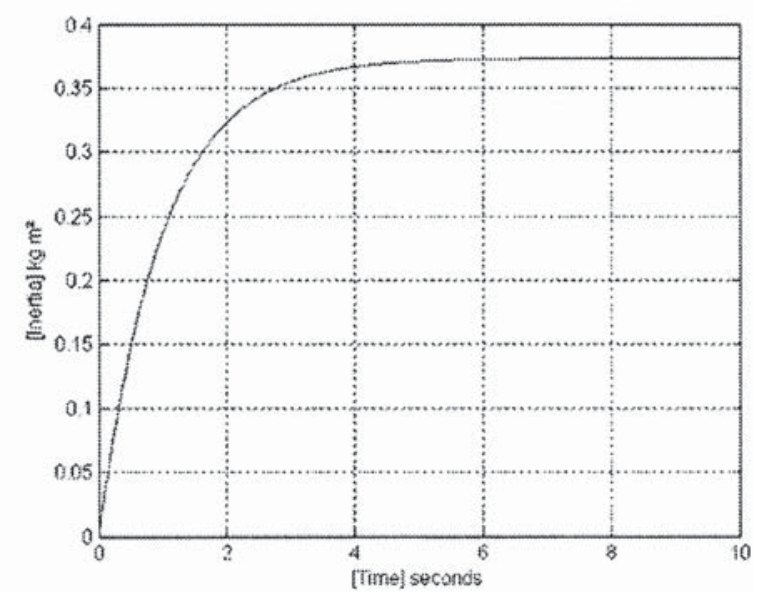

Fig. 12 Simulation results of system identification: (a) platform mass estimation; (b) platform inertia estimation 
parameter estimations for the platform mass $M_{\mathrm{P}}$ and the platform inertia $J_{\mathrm{P}}$ are obtained.

\subsection{Experimental results}

The experimental results show the same trend as the simulation results. For comparison with previous work, Fig. 13 shows the experimental result of the dynamic platform response when applying Feedforward and Active Force loops [5] and using no position feedback control. A significant vertical drift can be seen.

Figure 14 shows the experimental result using the Equilibrium Point controller and using no position feedback control. This control scheme outlines good performance compared to the Feedforward and Active Force control loops (Fig. 13) in terms of better drift attenuation.

Figures 15 and 16 show the obtained results using the Drift Compensation controller in combination with the Equilibrium Point controller. Without a base motion estimation the platform displayed a vertical low-frequency sinusoidal drift with respect to the desired position (Fig. 15), whereas the Drift Compensation controller, when applied to the dynamic platform and utilizing the base motion estimation developed in section 4.2, resulted in complete attenuation of drift (Fig. 16). Slightly larger a)

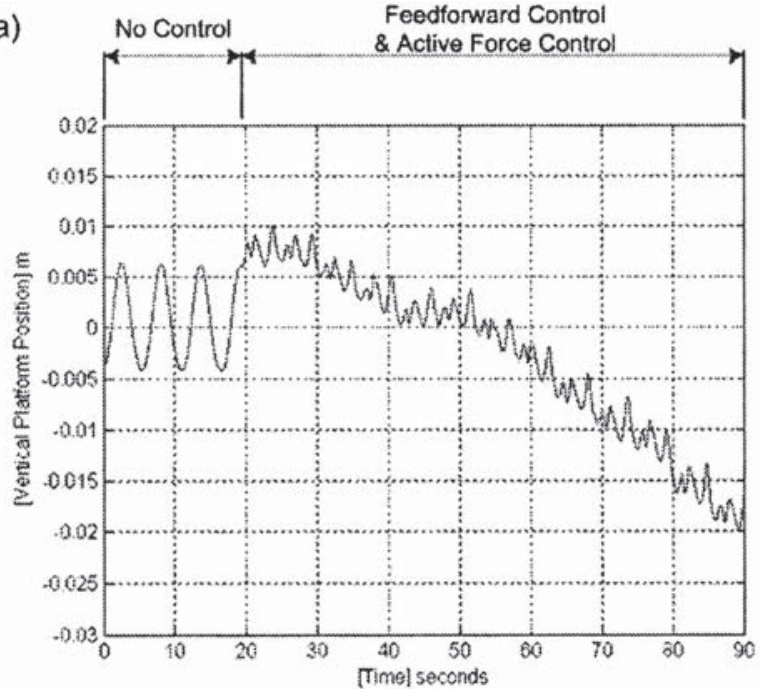

b)

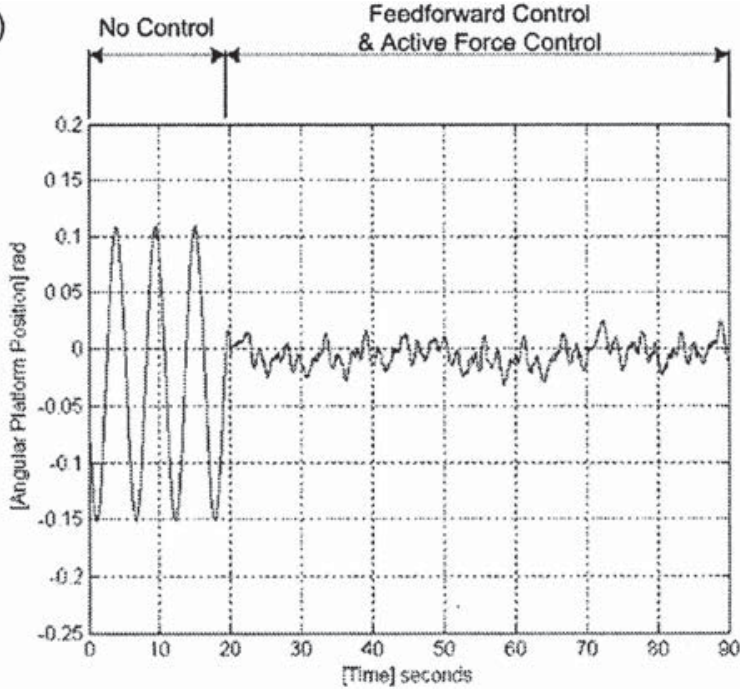

Fig. 13 Experimental results of the Feedforward controller and the Active Force controller [5]: (a) vertical platform position, $x$; (b) angular platform position, $\theta$
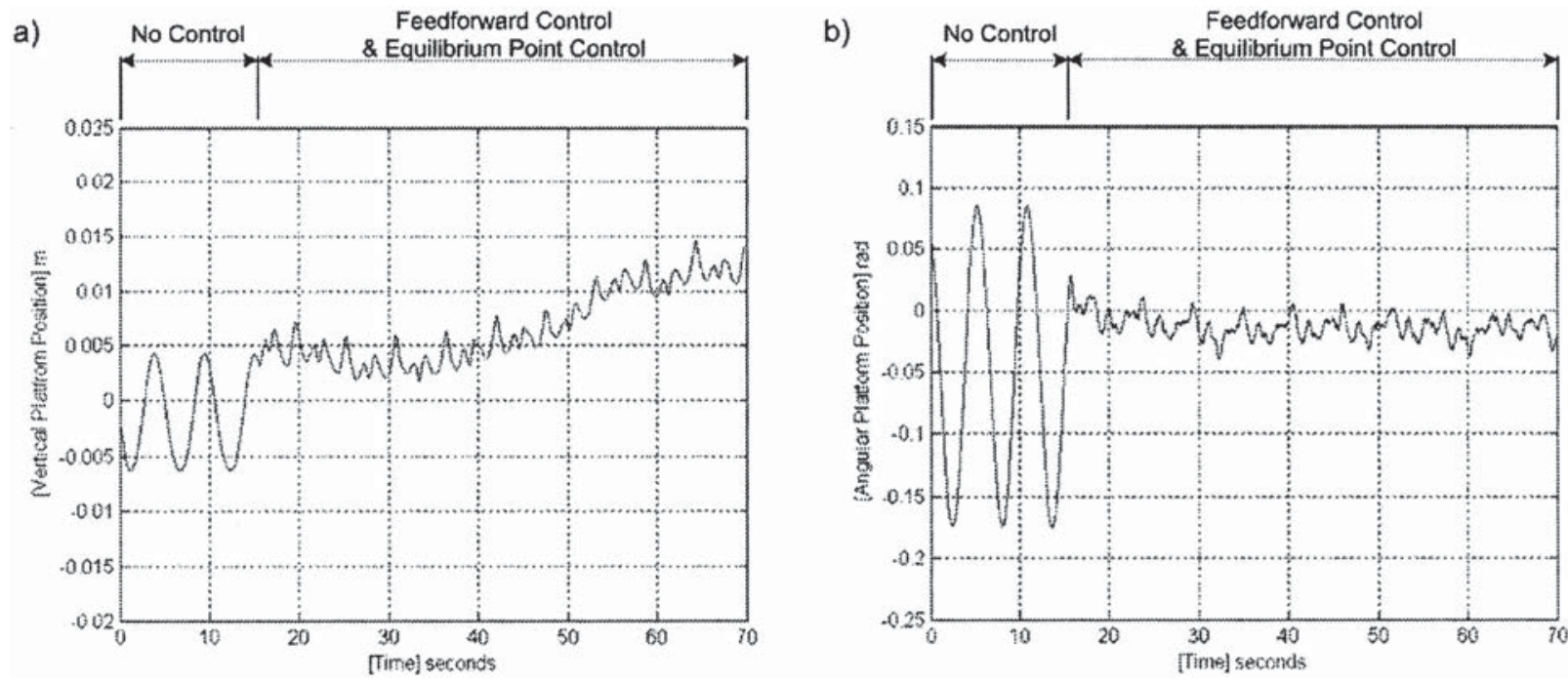

Fig. 14 Experimental results of the Equilibrium Point controller and the Feedforward controller: (a) vertical platform position, $x$; (b) angular platform position, $\theta$ 
a)

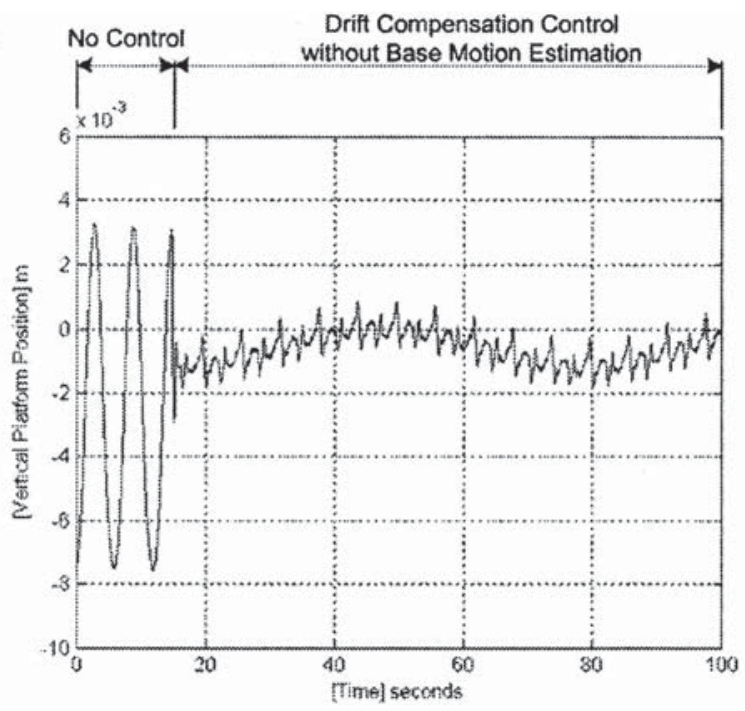

b)

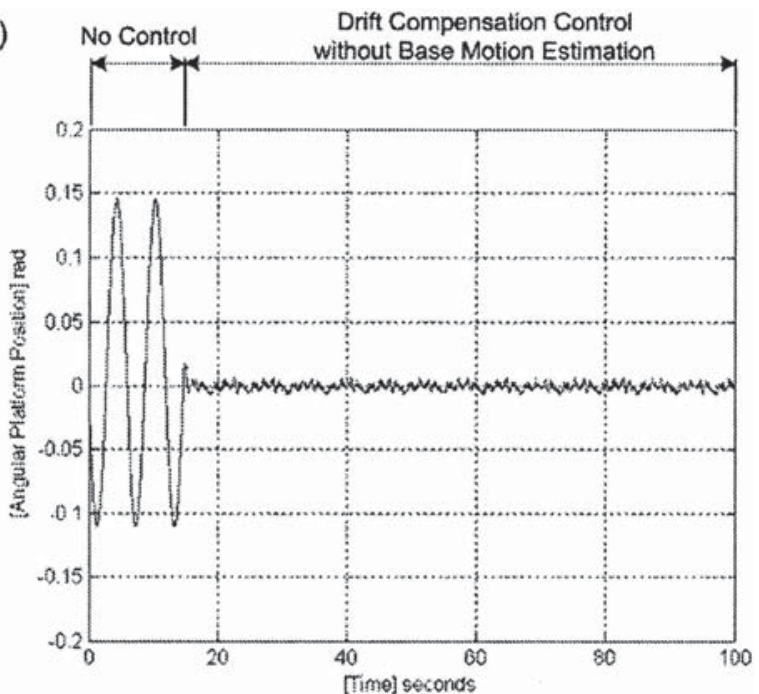

Fig. 15 Experimental results of the Drift Compensation controller and Equilibrium Point controller without a base motion estimation: (a) vertical platform position, $x$; (b) angular platform position, $\theta$

a)

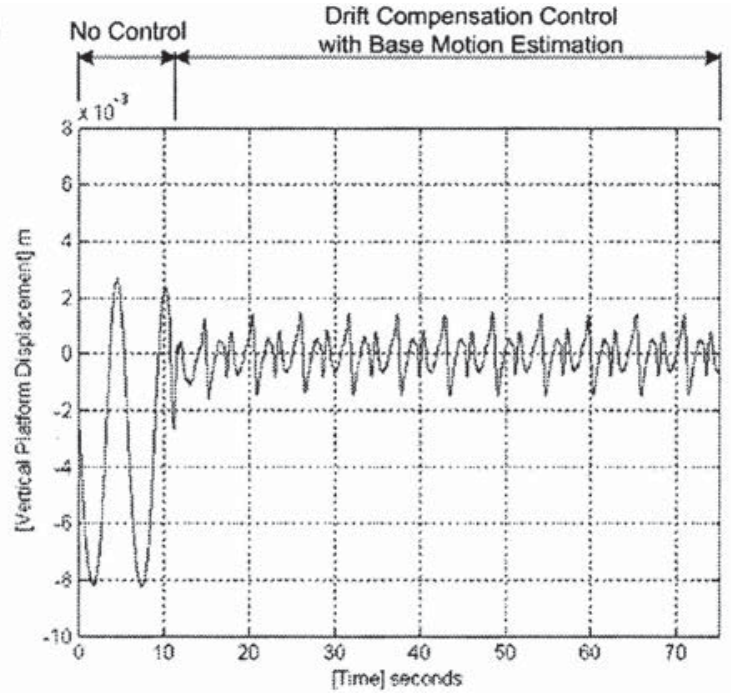

b)

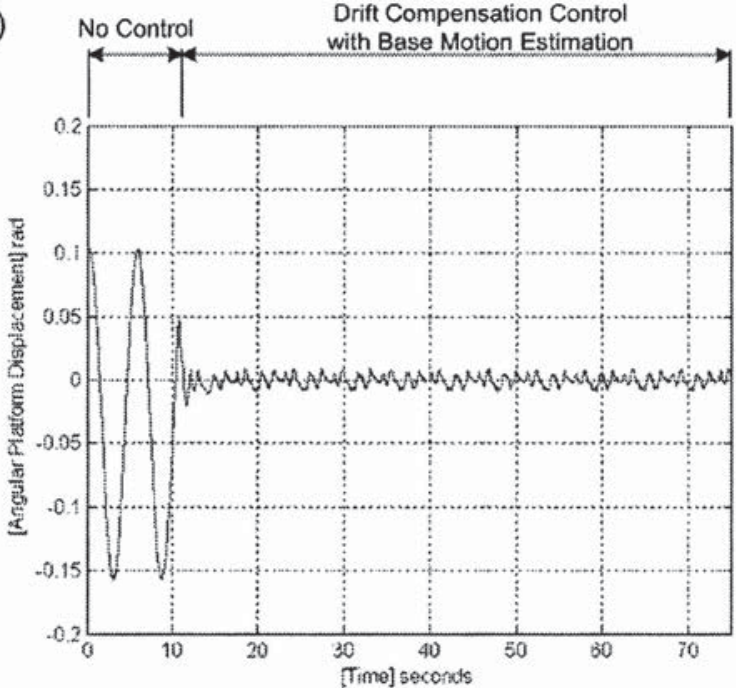

Fig. 16 Experimental results of the Drift Compensation controller and Equilibrium Point controller with a base motion estimation: (a) vertical platform position, $x$; (b) angular platform position, $\theta$

high-frequency vertical position errors of the platform, induced by the Drift Compensation controller, are observed.

Figure 17 shows the results obtained using the system identification. The Equilibrium Point controller and the Drift Compensation controller were applied all the time in order to avoid drift in the dynamic platform system. Due to hysteresis caused by the design of the force sensors and due to measurement errors, the results had to be filtered by a digital fourth-order Butterworth low-pass filter in order to obtain adequate parameter estimates. Consequently, longer delays were produced. After 20 seconds, acceptable results were obtained.

\section{CONCLUSIONS}

In this paper two control schemes have been described that can be applied to control dynamic platforms for offshore applications in adverse weather 
a)

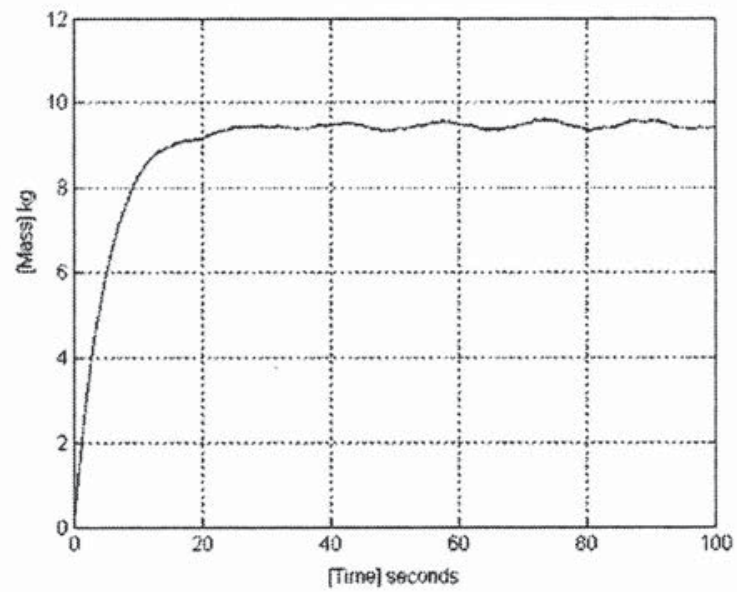

b)

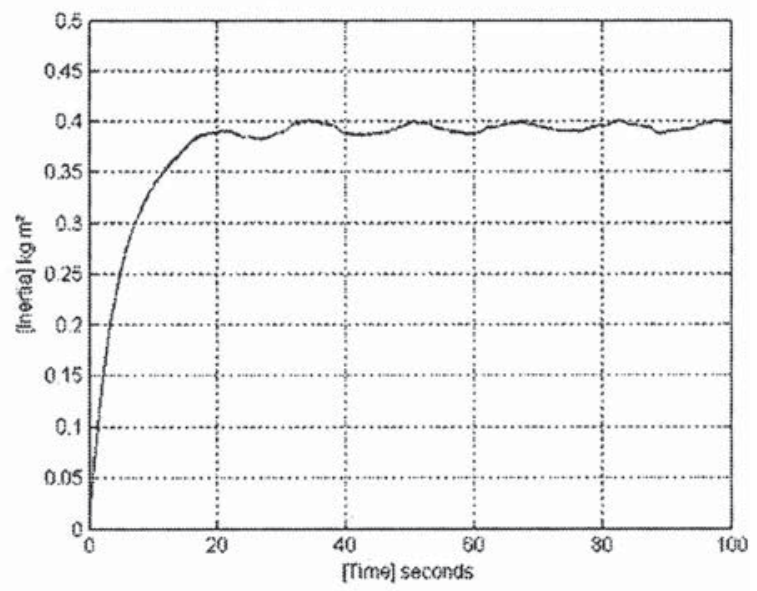

Fig. 17 Experimental results of system identification: (a) platform mass estimation; (b) platform inertia estimation

conditions to compensate for the effect of waveinduced disturbances and payload disturbances. The practical implementation of the dynamic platform and the measurement of the system state variables have been considered. It has been shown that the adopted control laws are very effective in isolating the dynamic platform, from displacement-type base disturbances and force/torque-type platform disturbances, when vertical (heave) position measurement is not possible. Normally, heave measurement could be obtained by satellite-supported measurement systems/units. However, in adverse weather conditions the satellite communication could be interrupted or slowed down and therefore effective control of the platform would not be possible. The proposed open-loop control strategy for the vertical motion could be implemented in parallel to satellite measurements to maintain accurate and fast vertical motion control. The control algorithms developed in this paper could be extended to higher-order dynamic platform systems.

\section{REFERENCES}

1 Love, L. J., Jansen, J. F., and Pin, F. G. Compensation of wave-induced motion and force phenomena for ship-based high performance robotic and human amplified systems, Oak Ridge National Laboratory, US Department of Energy, Tennessee, 2003.

2 Chalmers, H. and Sanders, R. The motion compensation deck handling system for the remote unmanned work system. In ASME OED Winter Annual Meeting Proceedings, Chicago, Illinois, November 1980.
3 Rhodes, Q. Z., Haney, J. D., and Carey, J. D. A low power/high performance active heave compensation system. In Proceedings of the Underwater Intervention 2002 Conference, New Orleans, Louisiana, February 2002.

4 Bhattacharyya, R. Dynamics of marine vehicles, 1978 (John Wiley, Chichester).

5 Bouazza-Marouf, K. and Hewit, J. R. Control of a dynamic platform for offshore applications. Mechatronics, 1993, 3(5), 589-609.

6 Price, W. Dynamics of ships, 1991 (Scholium International).

7 Levine, S. W. The control handbook, 1996 (CRC Press, Boca Raton, Florida).

8 Yager, T. The QNX operating system. Byte, August 1990, 15(80), 281-283.

\section{APPENDIX}

\section{Notation}

\begin{tabular}{|c|c|}
\hline $\mathbf{A}$ & system matrix \\
\hline C & controller output vector \\
\hline$C_{\mathrm{B}}$ & $\begin{array}{l}\text { base disturbance compensation control } \\
\text { vector }\end{array}$ \\
\hline$C_{\mathrm{C}}$ & $\begin{array}{l}\text { controller output vector derived from } \\
\text { system error }\end{array}$ \\
\hline$C_{\mathrm{D}}$ & $\begin{array}{l}\text { controller output vector for disturbance } \\
\text { cancellation or reduction }\end{array}$ \\
\hline$C_{\mathrm{E}}$ & Active Force control vector \\
\hline $\boldsymbol{C}_{\mathrm{EMF}}$ & back e.m.f. compensation control vector \\
\hline$C_{\mathrm{f}}$ & viscous friction coefficient ( $\mathrm{N} \mathrm{m} \mathrm{s/rad)}$ \\
\hline $\boldsymbol{C}_{\mathrm{F}}$ & friction compensation control vector \\
\hline $\boldsymbol{C}_{\mathrm{FFW}}$ & Feedforward control vector \\
\hline $\boldsymbol{E}$ & position difference vector \\
\hline
\end{tabular}




\begin{tabular}{|c|c|c|c|}
\hline $\boldsymbol{E}_{0}$ & initial position difference vector & $R_{\mathrm{B}}$ & ball screw mean radius (m) \\
\hline $\boldsymbol{F}$ & actuators' force vector & $R_{\mathrm{T}}$ & motor terminal resistance $(\Omega)$ \\
\hline$F_{1}, F_{2}$ & actuator forces on the platform $(\mathrm{N})$ & $T$ & actuators' force vector \\
\hline $\boldsymbol{F}_{\mathrm{AC}}$ & $\begin{array}{l}\text { high-frequency part of actuators' force } \\
\text { vector }\end{array}$ & $\boldsymbol{T}_{\mathrm{E}}$ & $\begin{array}{l}\text { actuator's unknown back e.m.f. torque } \\
\text { vector }\end{array}$ \\
\hline $\boldsymbol{F}_{\mathrm{D}}$ & disturbance vector & $\boldsymbol{T}_{\mathrm{F}}$ & actuator's unknown fictional torque vector \\
\hline $\boldsymbol{F}_{\mathrm{DC}}$ & $\begin{array}{l}\text { low-frequency part of actuators' force } \\
\text { vector }\end{array}$ & $\begin{array}{l}T_{\mathrm{L}} \\
V\end{array}$ & disturbance torque $(\mathrm{N} \mathrm{m})$ \\
\hline$F_{\mathrm{L}}$ & disturbance force $(\mathrm{N})$ & $V_{1}, V_{2}$ & actuator input voltages $(\mathrm{V})$ \\
\hline $\begin{array}{l}\boldsymbol{F}_{\mathrm{TD}} \\
\mathbf{G}_{\mathrm{P}}, \mathbf{G}_{\mathrm{I}}\end{array}$ & $\begin{array}{l}\text { overall disturbance vector } \\
\text { diagonal matrices representing drift }\end{array}$ & & $\begin{array}{l}\text { vertical (heave) displacement of the } \\
\text { platform (m) }\end{array}$ \\
\hline & compensation controller parameters & $\boldsymbol{X}$ & position (state) vector of the platform \\
\hline $\mathbf{H}$ & $\begin{array}{l}\text { diagonal matrix representing the transfer } \\
\text { functions of high-pass filters }\end{array}$ & $y$ & $\begin{array}{l}\text { vertical (heave) displacement of the base } \\
\text { (m) }\end{array}$ \\
\hline $\begin{array}{l}\mathbf{I} \\
J_{\mathrm{A}}\end{array}$ & $\begin{array}{l}\text { identity matrix } \\
\text { inertia of the actuator }\left(\mathrm{kg} \mathrm{m}^{2}\right)\end{array}$ & $\boldsymbol{Y}$ & position (state) vector of the base \\
\hline $\begin{array}{l}J_{\mathrm{P}} \\
K_{\mathrm{B}}\end{array}$ & $\begin{array}{l}\text { inertia of the platform }\left(\mathrm{kg} \mathrm{m}^{2}\right) \\
\text { gear ratio of a ball screw }(\mathrm{rad} / \mathrm{m})\end{array}$ & $\alpha_{1}, \alpha_{2}$ & angles between the platform and the \\
\hline$K_{\mathrm{E}}$ & motor back e.m.f. constant (V s/rad) & $\theta$ & angular (pitch) displacement of the \\
\hline$K_{\mathrm{T}}$ & motor torque constant (N m/A) & & platform (rad) \\
\hline $\mathbf{L}, \mathbf{L}_{\mathrm{E}}$ & $\begin{array}{l}\text { diagonal matrix representing the transfer } \\
\text { functions of low-pass filters }\end{array}$ & $\phi$ & $\begin{array}{l}\text { phase shift of the sinusoidal base heave } \\
\text { motion (rad) }\end{array}$ \\
\hline $\begin{array}{l}\mathbf{M} \\
M_{\mathrm{P}}\end{array}$ & $\begin{array}{l}\text { mass matrix } \\
\text { mass of platform }(\mathrm{kg})\end{array}$ & $\varphi$ & $\begin{array}{l}\text { angular (pitch) displacement of the base } \\
\text { (rad) }\end{array}$ \\
\hline $\begin{array}{l}Q \\
R\end{array}$ & $\begin{array}{l}\text { disturbance vector } \\
\text { distance between the platform centroid }\end{array}$ & $\omega$ & $\begin{array}{l}\text { frequency of the sinusoidal base heave } \\
\text { motion }(\mathrm{rad} / \mathrm{s})\end{array}$ \\
\hline
\end{tabular}

